\title{
Comparison of Medicaid and Non-Medicaid Dental Providers
}

\author{
W. Paul Lang, DDS, MPH \\ Assistant Professor \\ Department of Community Dentistry \\ School of Dentistry \\ Jane A. Weintraub, DDS, MPH \\ Assistant Professor \\ Program in Dental Public Health \\ School of Public Health \\ University of Michigan \\ Ann Arbor, Ml 48109
}

specified federal requirements, and other optional criteria and services that can be determined by each state. The provision of dental services is not one of the basic services required by Title XIX of the Social Security Act (2). A 1967 amendment establishing the Early and Periodic Screening, Diagnosis, and Treatment (EPSDT) benefit, required dental services to be included for eligible children under 21 years of age for all state Medicaid programs (3).

Medicaid-eligible persons also may receive dental care as an optional service in many states (4). A survey of states conducted by the American Dental Association (ADA) in 1984 to determine the availability of dental Medicaid benefits found that while Medicaid programs in most states offered dental services to selected children, services for even more carefully selected adults remained limited-and, in some states, were nonexistent (5). Patient copayments for dental services also are required in 10 states (6).

Because Medicaid does not have a strong vocal constituency, the program over the years since its enactment has been subject to cutbacks in services and eligibility (1). Dental services in many state Medicaid programs have been vulnerable to these cutbacks $(7,8)$.

In Michigan, a range of routine dental services has been available for children as Medicaid benefits since April 1973. A limited program for a specific group of adults was begun in fall 1973 with an additional group of adults added in 1974. Until 1985, services for adults were generally limited to emergency visits and removable prostheses. In 1984, over one million persons $(1,187,579)$ were eligible for Medicaid in Michigan, an increase of 25 percent since 1980 . Only one-fourth of these individuals $(293,003)$ received any dental services; 79 percent of the dental recipients were children (5). Of the dentists in Michigan, only about one-third actively participate in the Medicaid program (9). It appears that a limited number of Medicaid-eligible persons receive dental services in a given year and that this

+Norris R, Regional Dental Consultant, Dental Division, Department of Social Services, State of Michigan. Personal communication, Dec 12, 1985. 
care is provided by a self-selected group of dentists. The purpose of this analysis was to compare characteristics of dentists in Michigan who did and did not treat Medicaid-eligible patients, in order to substantiate and quantify perceptions of these providers that previously have been based on personal experiences of health professionals or anecdotal information. Furthermore, because national information about the dental component of Medicaid is limited, examination of the program on a state-by-state basis can provide insight into this dental care system.

\section{Methods}

Data were collected by a mail survey of a sample of general dentists practicing in Michigan in 1983. A representative cross-section of Michigan dentists was selected using a stratified systematic sampling scheme. The sample was drawn from all Michigan dentists categorized as general practitioners in the 1982 American Dental Directory of the American Dental Association, a list of dentists that contains demographic information about members and nonmembers (10). The registry listed 4,022 dentists as general practitioners in Michigan. The population was stratified by age and Health Service Area (11) for regional sampling and data analysis. Because more than half of the dentists resided in southeastern Michigan, the remainder of the state was oversampled to ensure that sufficient subjects would be available for regional analysis. Only dentists aged 65 and younger were sampled; dentists over 65 were considered to be less representative of the active general practitioner. An announcement of the impending survey was placed in the journal of the state dental society. After pretesting of the survey instrument, the questionnaire, a cover letter, and a preaddressed stamped return envelope were mailed to dentists in the sample. The initial mailing was followed by a reminder card and a second mailing to nonrespondents. The sample contained 640 dentists.

Respondents were asked to estimate the percentage of their patients receiving care under four different reimbursement mechanisms: dental insurance, direct out-of-pocket payment, government programs, and capitation. Patients who receive care reimbursed by government programs are predominantly Medicaid-eligible. Children participating in Head Start are also included in this category. To determine if differences existed between dentists who treated Medicaid patients and dentists who did not, respondents were stratified into three groups according to the percentage of patients in their practices who were reported to be Medicaid recipients. The extent of any differences among the three groups was determined using the Kruskal-Wallis test; differences between individual groups were assessed using the Mann-Whitney $U$ test with the Bonferroni correction $(P=.017)(12)$. A stepwise discriminant function analysis was performed to identify potential discriminator variables between groups. Regional differences in reimbursement sources for dental care were examined by stratifying respondents by Metropolitan Statistical Area (MSA) (13) and then testing for significant differences using the MannWhitney $\mathrm{U}$ test. Changes in percentages of patients treated under the various reimbursement mechanisms over time were determined for three Michigan counties by comparing data from a longitudinal survey of dentists conducted between 1974 and 1977 (14-16) with data from the current survey.

\section{Results}

After two mailings, 261 questionnaires were returned, yielding a 41 percent response rate. Nonresponse bias was assessed by the comparison of the age and location of respondents to these variables for the entire population of general practitioners in Michigan (10). The age distribution of respondents was similar to that of the dentist population; weighting the sample to correspond to the locations of the total population of general dentists in the state did not change the results. As shown in Figure 1, about half $(\mathrm{N}=115)$ of the 261 respondents said they did not accept Medicaid patients; these dentists comprised Group 1. Twenty-nine percent $(n=70)$ of all respondents reported having patient populations that contained some but less than 10 percent Medicaid-eligible patients (Group 2). Group 3 $(n=53)$, accounting for 22.3 percent of the respondents, included dentists who reported having patient populations that were composed of greater than or

\section{A dentist who becomes accustomed to receiving a higher fee for a particular service may not be willing to perform that service for a lower fee despite a self-perceived lack of busyness.}

equal to 10 percent Medicaid-eligible persons. Twentythree dentists did not provide this information. Sample sizes vary in Tables 1 and 2 because some respondents did not complete every question in the survey.

Table 1 displays characteristics of these three groups. Significant differences were observed among the three groups for median age, median years in practice, and median numbers of new patients/month using the Kruskal-Wallis test. When differences between individual groups were tested using the Mann-Whitney U test, the same three variables were found to be significant with the exception of the difference in median numbers of new patients/month between Groups 1 and 2. Thus dentists who reported more government-sponsored patients tended to be younger, had been in practice fewer years, and were seeing greater numbers of new patients each month. Dentists who were providing care to Medicaid recipients were more likely to be in a group practice than dentists who reported seeing no Medicaid recipients. Although differences were not statistically significant, a trend of decreasing net income was observed among the groups as the percentage of Medicaid patients increased. In all three groups, more than 40 percent reported themselves as being not busy enough. 
FIGURE 1

Distribution of Respondents by Percent of Patient Population with Care Reimbursed by Government Programs, Michigan 1982

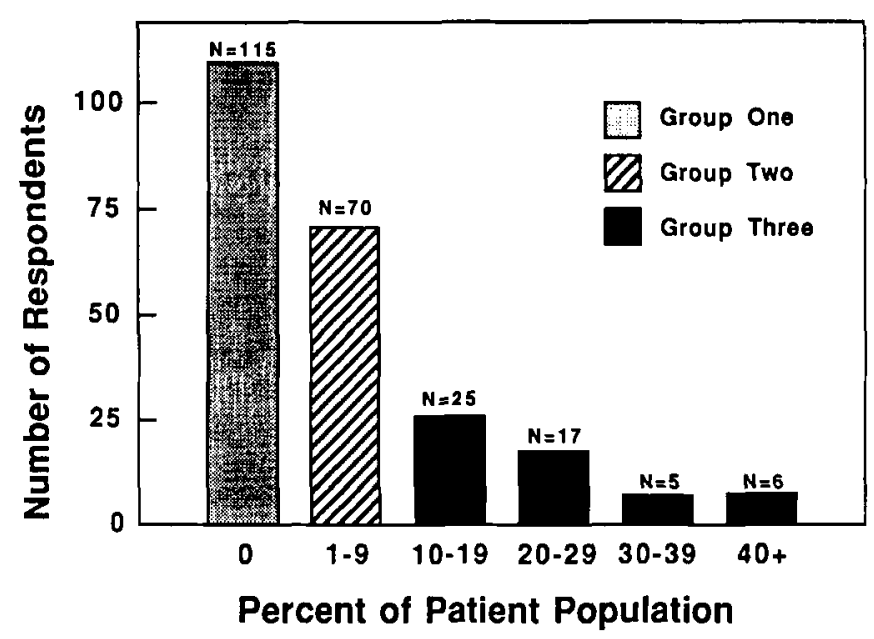

A stepwise discriminant function analysis of six practitioner characteristics (age of dentist, years in practice, new patients/month, appointments/week, patients on file in 1982, net income) was performed to identify potential discriminator variables between the three groups. Of the six variables, age of dentist $(\mathrm{P}<.001)$ and number of new patients/month $(\mathrm{P}=.041)$ were found to be significant.

When reimbursement sources were examined, differences were found between dentists living in metro- politan and those living in nonmetropolitan areas of the state. Table 2 displays reported reimbursement sources for all respondents and for dentists working in rural and urban counties. Respondents in rural counties reported that a smaller percentage of their patients had dental insurance, and a greater percentage of patients paid for care out-of-pocket or had their care reimbursed by government programs. These differences were found to be significant (see Table 2). Sixty-eight percent of rural providers reported some Medicaid patients in their practices, compared to only 43 percent of urban respondents.

Changes in the percentages of patients treated under different reimbursement mechanisms between 1974 and 1982 can be observed in Table 3. Responses from dentists in three Michigan counties who participated in a longitudinal survey from 1974 to 1976 (14-16) were compared to responses from dentists in the same counties who completed the current survey. Although these data were reported by two different groups of dentists, differences in the percentage of patients covered by various reimbursement mechanisms are apparent. The percentage of patients covered by dental insurance increased from about 40 to 70 percent, while the percentage of patients covered by government programs decreased from 17 to four percent. The category of "other," which included patients who paid for care outof-pocket, also declined. The small number of dentists from these three counties who responded to the 1983 survey and the demographic characteristics of these counties (to be described), limit to some degree the ability to generalize from these findings.

TABLE 1

Characteristics of General Practitioners-Michigan, 1983

\begin{tabular}{|c|c|c|c|c|c|c|c|}
\hline Characteristic & $\begin{array}{c}\text { Group } 1 \\
\text { No Medicaid } \\
\text { Patients }\end{array}$ & $(\mathrm{N})$ & $\begin{array}{l}\text { Group } 2 \\
<10 \% \text { Med } \\
\text { Patients }\end{array}$ & $(\mathrm{N})$ & $\begin{array}{c}\text { Group } 3 \\
\geq 10 \% \text { Med. } \\
\text { Patients }\end{array}$ & $(\mathrm{N})$ & Significance $^{*}$ \\
\hline Median age & 47.0 & $(115)$ & 41.0 & $(70)$ & 33.0 & $(53)$ & $\mathrm{P}<.001$ \\
\hline Median years in practice & 18.0 & (115) & 9.0 & (69) & 6.0 & (53) & $P<.001$ \\
\hline Median \# new patients/month & 10.0 & (111) & 10.0 & (69) & 18.0 & (50) & $\mathrm{P}=.012$ \\
\hline Median \# appts./week & 60.0 & (107) & 60.0 & (67) & 55.0 & (52) & \\
\hline Median \# patients/1982 & $2,000.0$ & $(97)$ & $2,000.0$ & (55) & $1,600.0$ & (43) & \\
\hline Median net income & $\$ 60,000$ & (94) & $\$ 56,273$ & (54) & $\$ 48,000$ & (38) & \\
\hline Percent in group practice & $17.4 \%$ & (115) & $24.3 \%$ & (70) & $28.3 \%$ & (53) & \\
\hline Percent "not busy enough" & $46.1 \%$ & (115) & $42.9 \%$ & (70) & $52.8 \%$ & (53) & \\
\hline
\end{tabular}

"Kruskal Wallis test.

TABLE 2

Percent Distribution of Reimbursement Sources-Michigan, 1982

\begin{tabular}{lcccccc}
\hline & \multicolumn{2}{c}{ Urban Counties $(\mathrm{N}=159)$} & & \multicolumn{2}{c}{ Rural Counties $(\mathrm{N}=75)$} \\
Source & Median & (Range) & & Median & (Range) & Significance* \\
\hline Dental insurance & 75.0 & $(30.0-97.0)$ & & 60.0 & $(20.0-90.0)$ & $\mathrm{P}<.001$ \\
Out-of-pocket & 20.0 & $(1.0-70.0)$ & & 30.0 & $(10.0-70.0)$ & $\mathrm{P}=.002$ \\
Government programs & 0.0 & $(0.0-60.0)$ & & 5.0 & $(0.0-60.0)$ & $\mathrm{P}<.001$ \\
Capitation & 0.0 & $(0.0-30.0)$ & & 0.0 & $(0.0-10.0)$ & \\
\hline
\end{tabular}

*Mann-Whitney U test. 
TABLE 3

Percent Distribution of Reimbursement Sources for Three Michigan Counties, 1974 and 1982

\begin{tabular}{lcc}
\hline Source & $1974(\mathrm{~N}=434)$ & $1982(\mathrm{~N}=37)$ \\
\hline Dental insurance & 43.8 & 70.1 \\
Government programs & 16.8 & 4.1 \\
Other & 39.4 & 25.8 \\
\hline
\end{tabular}

\section{Discussion}

Analysis of these data suggests that dentists who treat the Medicaid-eligible are younger, are more likely to be in group practices, and are seeing more new patients each month. The last characteristic may be indicative of the willingness of younger dentists to accept new patients regardless of the reimbursement source in order to fill appointment time. Also, dentists who accept Medicaid patients may be scheduling more new patients because of the likelihood that these individuals may break appointments or not follow through with treatment plans (17). It is not known whether younger dentists will continue to accept Medicaid patients over time. Comparison of the three groups suggests a trend of decreasing provider participation in government programs as dentists' practices become more established. Several factors may be present that act as deterrents for more established practitioners to accept Medicaid patients despite the presence of a large eligible population and self-reported lack of busyness.

An inadequate fee schedule was the most frequently cited reason for dentists not regularly treating Medicaid patients, according to a 1978 ADA survey (18). In Table 4 , fees of general practitioners compiled by the ADA in 1982 (19) and Medicaid reimbursement levels for 1981 found by Prokup and Manning (20) via a survey of states are presented for several selected services. The differences between these fees are substantial.

An example of fee disparities was demonstrated in Michigan in 1985 when additional Medicaid benefits for adults became available. Instead of reimbursing dentists for each service provided during an initial appointment, three frequently performed procedures (initial examination, prophylaxis, and bitewing radiographs) were reimbursed at a flat rate of about $\$ 20$. Median fees reported by dentists in 1982 for these same services were as follows: initial examination- $\$ 10$, prophylax- is- $\$ 20$, and bitewing radiographs- $\$ 10(19)$. A fee disparity of this magnitude may represent a greater barrier to acceptance of Medicaid patients by older dentists because of higher expectations of the perceived value of their services. A dentist who becomes accustomed to receiving a higher fee for a particular service may not be willing to perform that service for a lower fee despite a self-perceived lack of busyness. Even during the economic recession of the early 1980s, increased treatment of Medicaid patients was not observed among Michigan dentists (21).

Other factors affecting dentists' participation in the Medicaid program include dissatisfaction with treatment review procedures and restrictions in reimbursable services compared to private dental insurance (16), delays in receiving payments $(16,22)$, and frequent broken appointments by Medicaid patients $(17,22)$. Increasing familiarity with these problems may be a likely cause of declining Medicaid participation by older dentists.

Another contributing factor may be the growth of private dental insurance in the last decade. Dentists, when possible, may replace government-sponsored patients with private dental insurance patients. Prior to the implementation of a dental benefits program for automobile employees, Malvitz and others (14-16) surveyed dentists in three Michigan counties to gather baseline information concerning practice characteristics of dentists. Three counties were selected: Genesee and Saginaw counties, where a large proportion of the work force was to receive dental benefits, and Kent County, where benefits were not prevalent. Comparisons with 1982 reimbursement sources suggest declines in the percentages of patients whose care was reimbursed by government programs and other sources, along with a concomitant increase in dental insurance as a reimbursement source. The enlarging pool of patients with dental insurance may also have contributed to declining participation in government programs by dentists.

Differences were found in the geographic distribution of Medicaid patients and of dentists who would accept Medicaid patients. Eighty-two percent of Medicaid-eligible patients in Michigan reside in metropolitan areas (9), yet 57 percent of respondents who practiced in urban areas did not accept Medicaid patients. In contrast, in rural areas, low-income persons, although fewer in absolute number, comprise a larger percentage

TABLE 4

Mean Dental Fees for Selected Services

\begin{tabular}{lcccc}
\hline Service & Medicaid* & \multicolumn{1}{c}{ ADAt } & \multicolumn{1}{c}{ S.D. } \\
\hline Adult prophylaxis & 1981 & S.D. & $(982$ & $(6.15)$ \\
Composite (1 surface) & $\$ 14.21$ & $(3.16)$ & $\$ 22.41$ & $(9.01)$ \\
Amalgam (2 surface) & $\$ 14.34$ & $(3.42)$ & $\$ 24.93$ & $(7.66)$ \\
Simple extraction & $\$ 17.94$ & $(4.01)$ & $\$ 30.35$ & $(12.60)$ \\
Upper denture & $\$ 12.84$ & $(3.78)$ & $\$ 33.77$ & $(146.58)$ \\
\hline
\end{tabular}

*Prokup B, Manning M. NYS Dent J 1982;48:38-41.

tAmerican Dental Association Bureau of Economic and Behavioral Research. J Am Dent Assoc 1984;108:83-7. 
of the population (23). Thus the finding that providers in rural areas were more likely to accept Medicaid patients was not surprising. Pollard and coworkers (24) compared the numbers of dentists receiving Medicaid reimbursement in two geographic areas in New York State between 1970 and 1973. A trend of increased participation by upstate dentists and decreased participation by dentists in New York City was observed. They suggested that changes in participation were related to economic differences in these two areas.

In the current climate of cost containment, the prospect for increasing the supply of dentists willing to provide care for low-income families appears bleak because Medicaid reimbursement levels are not likely to change dramatically. Without new economic incentives or improvements in provider attitudes, differences among Medicaid and non-Medicaid practitioners found by this analysis probably will remain. Developing creative methods to supplement Medicaid funds with other public resources and to stimulate continued interest among providers to care for low-income persons will challenge the resourcefulness of public health professionals in the future.

\section{Conclusions}

1. Younger dentists are more likely to treat persons whose care is reimbursed by government programs.

2. Participation in government programs appears to decline with dentist and dental practice maturity.

3. When possible, dentists are likely to replace government sponsored patients with dental insurance patients.

4. Michigan dentists in rural areas are more likely to have patient populations containing Medicaid-eligible persons than dentists in urban areas.

\section{References}

1. Glenn K, ed. Twenty years of Medicaid. Washington Report on Medicine and Health. Washington DC: McGraw-Hill, July 29, 1985;39(10): Suppl.

2. Sawyer D, Ruther M, Pagan-Berlucchi A, Muse DN. The Medicare and Medicaid data book, 1983. Baltimore, Maryland: Health Care Financing Administration, Office of Research and Demonstrations, 1983; HCFA Pub. No. 03156.

3. Mueller, CD. Medicaid and use of dental services by children. Rockville, Maryland: Public Health Service, National Center for Health Services Research, 1984; NCHSR Pub. No. 84-224.

4. US Department of Health and Human Services, Health Care Financing Administration. Health Care Financing. Program Statistics. Analysis of state Medicaid program characteristics, 1984 Washington, DC: Govt. Printing Office, 1985; HCFA Pub. No. 03204 .
5. American Dental Association, Council on Dental Care Programs. Dental programs in Medicaid: Report of a survey. Chicago: American Dental Association, 1984.

6. US Department of Health and Human Services, Health Care Financing Administration. Health Care Financing. Grants and contracts report. Short-term evaluation of Medicaid: Selected issues. Washington, DC: Govt. Printing Office, 1984; HCFA Pub. No. 03186.

7. Anderson C. Missouri Medicaid program. J Missouri Dent Assoc 1982;62:22-6.

8. Pittman JL. A lesson from Medicaid (Editorial). J Mich Dent Assoc 1976;58:70-1.

9. Allen PM. Supplement to Request for Proposals and Quotations for the Dental Capitation Plan. Proceedings of a bidders conference in Lansing, Michigan. Lansing: [Michigan Department of Social Services], 1985;1-17.

10. American Dental Association. 1982 American Dental Directory. Chicago: American Dental Association, 1982.

11. US House of Representatives, Subcommittee on Health and the Environment, Committee on Interstate and Foreign Commerce. A discursive dictionary of health care. Washington, DC: Govt. Printing Office, 1976.

12. Glantz SA. Primer of Biostatistics. New York: McGraw-Hill, 1981.

13. US Department of Commerce, Bureau of the Census. Statistical abstract of the United States, 1984. Washington, DC: Govt. Printing Office, 1983.

14. Malvitz DM, Bader JD, Striffler DF. Study of the automobile employees' dental benefits. Part 2: Attitude of dentists in three Michigan counties. J Mich Dent Assoc 1975;57:307-12.

15. Malvitz DM, Bader JD, Striffler DF. Preliminary report on a study of the automobile employees' dental benefits. J Mich Dent Assoc 1975;57:278-82.

16. Eklund SA, Malvitz DM, Striffler DF. Report on a study of the automobile employees' dental benefits. Part 2: Attitudes of dentists in three Michigan counties after one and two years. J Mich Dent Assoc 1977;59:636-47.

17. Simpson R, Jakobsen J, Hayden H, Beck J, Ettinger R, Walz $T$. Dental care for the elderly and Title XIX patients in Iowa. J Iowa Dent Assoc 1979;65:35-7.

18. American Dental Association, Council on Dental Care Programs. Dental programs in Medicaid: Report of a survey. Chicago: American Dental Association, 1979.

19. American Dental Association Bureau of Economic and Behavioral Research. Dental fees charged by general practitioners and selected specialists in the United States, 1982. J Am Dent Assoc 1984;108:83-87.

20. Prokup B, Manning M. Medicaid dental reimbursement-New York State is low. NYS Dent J 1982;48:38-41.

21. Lang WP, Faja BW, Chasteen JE. The 1983 survey of general practice in Michigan: Patient characteristics, busyness, and reimbursement patterns. J Mich Dent Assoc 1986;68:146-51.

22. Thomas H. Care program in crisis: Medicaid. Provider's report on Indiana's Medicaid dental program. J Indiana Dent Assoc 1976; 55:8-12.

23. US Department of Commerce, Bureau of the Census. County and city data book, 1983. Money income and local government employment. Washington, DC: Govt. Printing Office, 1983.

24. Pollard ST, Leske GS, Haven EM. Dental Medicaid in New York State: history and data from the reporting system. J Public Health Dent 1975 Spring;35:109-17. 